\title{
Impact of intestinal health at poultry
}

\begin{abstract}
Aim: In this mini-review, we discuss the implications for the integrity of intestinal health in poultry production.
\end{abstract}

Keywords: microorganisms, composition intestinal, microflora
Volume I Issue 5 - 2017

\author{
Elizangela Bonfim de Oliveira,' Renata \\ Gomes da Silveira Deminicis,' Matheus \\ Ramalho de Lima, ${ }^{2}$ Fernando Guilherme \\ Perazzo Costa, ${ }^{3}$ Daniel Sales do \\ Nascimento, ${ }^{2}$ Talía Silva Ribeiro ${ }^{2}$ \\ 'State University of Santa Cruz, Animal Science, Brazil \\ ${ }^{2}$ Federal University of South of Bahia, Brazil \\ ${ }^{3}$ Federal University of Paraíba, Brazil
}

Correspondence: Elizangela Bonfim de Oliveira, Federal State University of Santa Cruz, Soane Nazaré de Andrade CampusHighway, Jorge Amado, km I6, Ilhéus, Bahia, Brazil,Tel +5 5779 8823 4234, Email elizbam@hotmail.com

Received: October 27, 2017 | Published: December 07, 2017

\section{Introduction}

Modern industrial poultry aims at high animal production, with low cost and quality. In order to obtain these points, it is necessary to use more and more technical production systems. However, high productivity will only be possible if the birds exhibit optimal intestinal health. With intestinal health absent in these animals, a high production will not be possible, even if a good quality diet and adequate environment is offered, since all food consumed will be eliminated without taking advantage of the nutrients present in the diet. Gastrointestinal health refers to the existence of a dynamic balance between the intestinal mucosa and the luminal content sufficient to achieve the expected performance goals (weight gain and feed conversion). However, there is still little attention to the control or manipulation of nutrient absorption in order to reduce the metabolic demand associated with these processes.

\section{Materials and methods}

\section{a. Gastrointestinal tract}

The chicken and chicken digestive system hosts a complex microbial community, participatory in several physiological processes, such as food digestion also in host Immunomodulation. ${ }^{1}$ The diversification of the intestinal microbiome allows innumerable interactions with the host to occur, thus exerting an important function for the growth of the animals, also contributing to their health. ${ }^{2}$ Throughout the intestinal tract, the microbial composition differs, that is, each section of the intestine has its own microenvironment, where the colonies of specific microorganisms that best identify with the site remain. ${ }^{3}$ In the duodenum, the $\mathrm{pH}$ is neutral and the microorganisms colonize this compartment, as well as the jejunum and ileum. While the cecum is considerably the site of higher colonization of microorganisms, being a large part of Gram positive and negative bacteria. ${ }^{4}$ It has increasingly recognized that the intestinal microbiota is an important component of chick health and thus the ability accurately stipulate its heterogeneity is effective in uncovering numerous ways to improve chick health. ${ }^{5}$

\section{b. Composition of intestinal microflora}

However, the composition of the intestinal microflora may be beneficial or harmful to the host, depending on the nature and amount of microorganisms. The beneficial microbiota consists of bacteria such as Lactobacillus spp, Bifidobacterium spp, Fusobacterium spp, Saccharomyces cerevisiae ${ }^{6}$ that act to inhibit the growth of pathogenic bacteria, stimulate the immune system, synthesize vitamins, reduce gas production and improve digestion and absorption of nutrients. Although they constituted in intestine, there are supplemental studies to improve the population of these bacteria. In a study, ${ }^{7}$ they evaluated the effect of long-term supplementation of Bacillus subtilis CGMCC 1,921 on performance, egg quality and fecal and c caecum 1 microbiota of laying hens, and concluded that long-term supplementation modulated the caecum microbiota by increasing bacterial proliferation such as Lactobacillus and Bifidobacterium, and by inhibiting possible pathogens, including E. coli and C. perfringens. According to, ${ }^{8}$ the bacteria that make up the intestinal microbiota only $10 \%$ considered harmful to host, among them are Escherichia coli, Clostridium spp., Salmonella spp. and Campylobacter sp. Enteric infections, can be caused by, mycotoxin-producing bacteria, viruses, protozoa, and fungi, including the progression from enteric infection to a systemic infection. ${ }^{9}$ Causing diarrhea, infections, liver disorders, carcinogenesis, intestinal putrefaction, reduced digestion, and nutrient absorption. These infections occur because of the imbalance of the beneficial intestinal microbiota, which favors the development of harmful bacteria, causing intestinal and bird health damage in general. ${ }^{10}$ Therefore, an imbalance in the intestinal microflora can cause great damages in the poultry production, either by the demand of food or due to lesions provoked in the intestinal mucosa by the pathogenic bacteria.

\section{Conclusion}

Although many technicians do not assess the importance of maintaining intestinal health integrity, they believe that the mechanisms of digestion and absorption only related to the physiology of the animals. Intestinal health can considered a prime factor for high production and lower cost in breeding systems. Because the health and performance of the birds linked to the intestinal microbiota, because the beneficial microorganisms aid in the digestion and absorption of the nutrients and in competition with the pathogenic microorganisms, 
consequently improves feed conversion and animal performance. While the harmful microorganisms can weaken the animals and still poses risks to public health, since the carcasses can contaminated and through consumption, transmit diseases to the man.

\section{Acknowledgements}

None.

\section{Conflict of interest}

The author declares there is no conflict of interest.

\section{References}

1. Tilocca B, Witzig M, Rodehutscord M, et al. Variability of phosphorus accessibility causing changes in microbioma functions in the gastrointestinal tract of broilers. PLoS One. 2016;(10):e0164735.

2. Oakley BB, Lillehoj HS, Kogut MH, et al. The chicken gastrointestinal microbiome. FEMS Microbiol Lett. 2014;360(2):100-112.

3. Videnska P, Faldynova M, Juricova H, et al. Chicken fecal microbiota and disorders induced by single or repeated therapy with tetracycline and streptomycin. BMC veterinary research. 2013;9:30.
4. Gabriel I, Lessire M, Mallet S, et al. Microflora of the digestive tract: critical factors and consequences for poultry. World's Poultry Science Journal. 2006;62(3):499-511.

5. Zhang Y, Simon SE, Johnson JA, et al. Spatial Microbial Composition along the Gastrointestinal Tract of Captive Attwater's Prairie Chicken. Microb Ecol. 2017;73(4):966-977.

6. PIRES DL. Effect of intestinal microbiota esophageal inoculation on hematology, development and intestinal integrity of cut chicks. 104 p. Dissertation (Master degree)-Faculty of Agrarian and Veterinary Sciences - Unesp, Jaboticabal. Brazil; 2008.

7. Guo JR, Dong XF, Liu S, et al. Effects of long-term Bacillus subtilis CGMCC 1.921 supplementation on performance, egg quality, and fecal and cecal microbiota of laying hens. Poultry Science. 2016;96(5):1280-1289.

8. Maiorka A. Impact of Intestinal Health on Poultry Productivity. Brazil; 2004. p. 119-129.

9. Loddi MM. Probiotics and prebiotics in bird nutrition. Magazine CFMV, Brasília, Brasília, Brazil; 2001;23:51-56.

10. Tamehiro CY, Alfieri AF, Alfieri AA. Enteric infections of viral origin. In: Revolledo L, Ferreira AJP, editors. Avian Pathology. Manole Ltda, Barueri, Brazil; 2009;24:245-257. 